\title{
A case of post-caesarean vesico-uterine fistula: a rare entity becoming common
}

\author{
Pallavee P.*, Jeetendra Behera, Rupal Samal
} Department of Obstetrics and Gynecology, Mahatma Gandhi Medical College and Research Institute, Pondicherry,
Puducherry, India

Received: 21 August 2017

Revised: 01 September 2017

Accepted: 16 September 2017

\author{
*Correspondence: \\ Dr. Pallavee P., \\ E-mail: ppallavee@rediffmail.com
}

Copyright: () the author(s), publisher and licensee Medip Academy. This is an open-access article distributed under the terms of the Creative Commons Attribution Non-Commercial License, which permits unrestricted non-commercial use, distribution, and reproduction in any medium, provided the original work is properly cited.

\begin{abstract}
Vesicouterine fistula (VUF) is rare, with an incidence estimated at $1-4 \%$ of all genitourinary fistulas. We report a case of VUF which was referred to our institute on the $6^{\text {th }}$ postoperative day following an emergency repeat lower section caesarean section (LSCS) at 39 weeks, with complaints of hematuria and watery discharge per vaginum for further management. Patient had stable vitals with slight abdominal distension and tenderness and watery discharge per vaginum having an ammoniacal odour. USG examination showed Foley's bulb inside uterine cavity. CT abdomen confirmed the findings and showed presence of contrast inside uterine cavity. Patient was re-operated on $9^{\text {th }}$ postoperative day in concurrence with urologists. Cystoscopy showed a $2 \mathrm{~cm}$ size fistulous opening. Intra-operative findings revealed a fistulous track between posterior wall of bladder and uterine incision. Appropriate reparative surgery was done. Obstetricians need to be aware of this condition particularly while operating on previous caesarean sections.
\end{abstract}

Keywords: Menouria, Post-caesarean, Vesico-uterine fistula, Youssef's syndrome

\section{INTRODUCTION}

Vesicouterine fistula (VUF) is rare and accounts for 1-4\% of all genitourinary fistulas. ${ }^{1}$ Majority [80-90\%] are caused during caesarean sections. Rising trend of lower section caesarean sections (LSCS) have led to an increased reporting of this complication. Intra-operative diagnosis and appropriate repair of bladder injury during a caesarean section can reduce the likelihood of encountering this iatrogenic complication and its medicolegal repercussions. An iatrogenic genitourinary fistula is an abnormal communication between the bladder or ureter and the uterus/cervix/ vagina, resulting from a surgical procedure. According to RCOG, the incidence of bladder injuries in caesarean sections is $\mathbf{1}$ in $\mathbf{1 0 0 0 .}$ Factors involved in the development of VUF secondary to LSCS include inadequate downward mobilization of the bladder, sutures inadvertently placed through the bladder wall, bladder devascularisation during dissection and infection secondary to catheterisation, or haematoma formation. It may have varied clinical picture with early or late presentation.

The present case seeks to increase awareness of this entity and possible methods of prevention amongst present day obstetricians.

\section{CASE REPORT}

Written and informed consent has been obtained from the patient for presentation of this case. A $26 \mathrm{yr}$ old female, P2L2, was rushed to our department with presenting 
complaints of abdominal distension and watery discharge PV. Her background obstetric history signified emergency repeat LSCS done in a district hospital 7 days prior. General examination findings showed that she was febrile, with stable vitals, slight abdominal distension with watery discharge through cervix seen on speculum examination. She had an indwelling catheter in place, with no hematuria and good urine output.

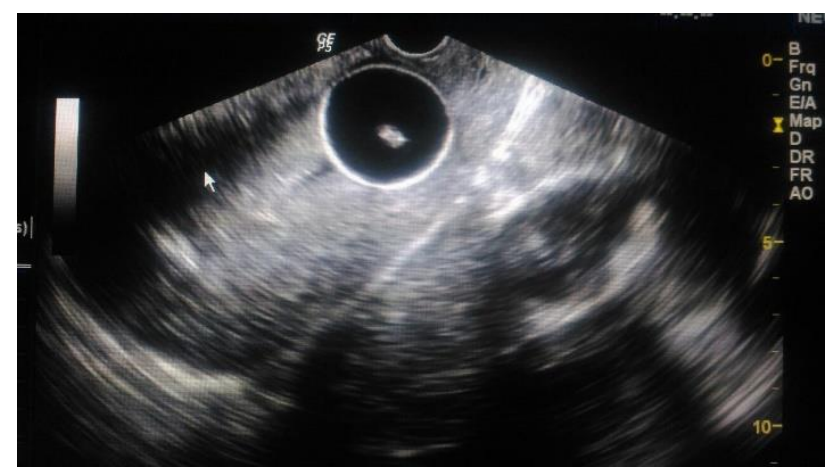

Figure 1: USG showing Foley's bulb inside uterine cavity.

All required investigations were carried out considering a multidisciplinary management approach. Transabdominal sonography showed the Foley's bulb inside the uterine cavity (Figure 1). Contrast enhanced computerized tomography (CECT) abdomen confirmed the findings and showed contrast inside the uterine cavity (Figure 2). Cystoscopy showed a $2 \mathrm{~cm}$ size fistulous opening in the supra-trigonal region. A diagnosis of vesicouterine fistula was confirmed.

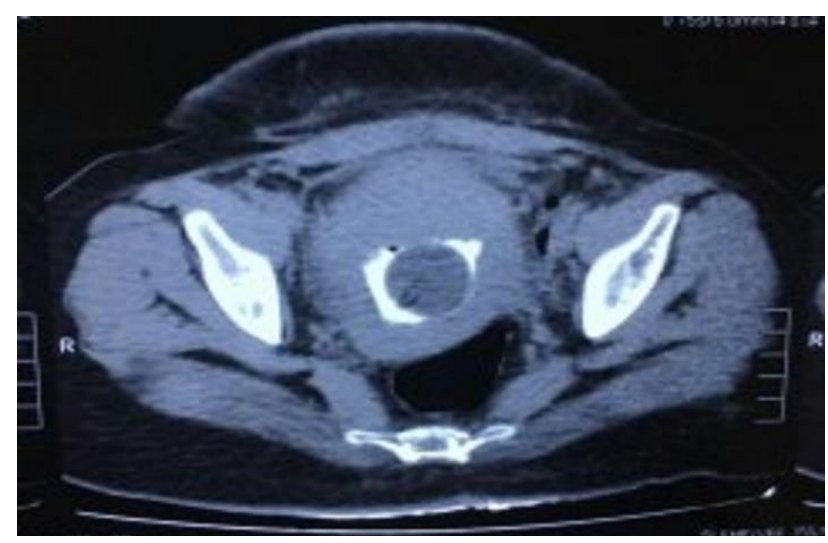

Figure 2: CECT abdomen showing contrast inside uterine cavity.

Exploratory laparatomy was performed in concurrence with urologists. Intra-operative findings confirmed communication between the supratrigonal region of bladder and the uterine incision (Figure 3). Layered closure of bladder and uterus with omental interposition was done. Continuous bladder drainage was continued for 10 days. Postoperative cystogram showed no urinary leak. Patient was discharged from hospital on 14th postoperative day.

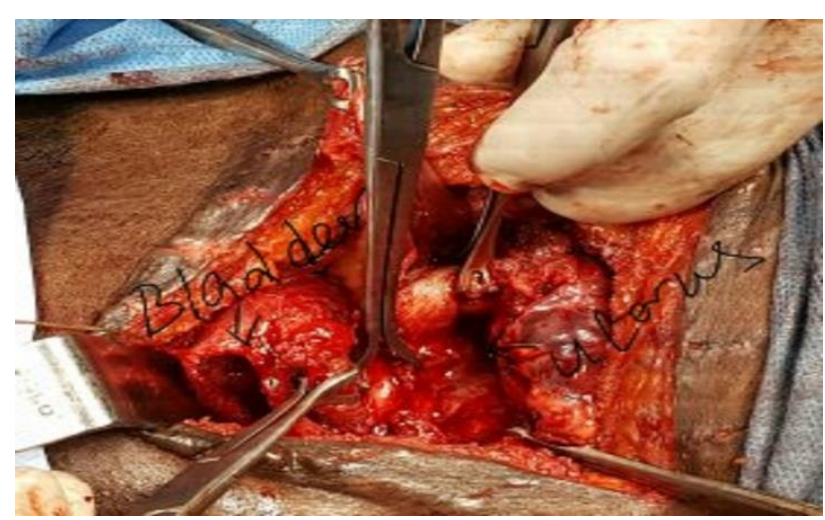

Figure 3: Intra-operative findings: communication between supratrigonal region of bladder and uterine incision.

\section{DISCUSSION}

Following unrecognised bladder injury, patients can present in the postoperative period with hematuria, ileus, urinary ascites, abdominal distension, peritonitis, sepsis and VUF. In post-caesarean patients having VUF, if the fistula lies superior to the level of the isthmus, ${ }^{2}$ symptomatology consists mainly of menouria or amenorrhoea, without urinary leakage, as menstrual blood passes into the bladder and intrauterine pressure never rises above isthmic sphincter pressure. This has been termed as Youssef's syndrome. If fistula lies below isthmus, patients present with urinary incontinence when the bladder pressure rises and normal menstruation ensues in such cases. ${ }^{3}$ Prevention of bladder injury during caesarean section requires good surgical techniques like tissue respect, hemostasis, correct closure, use of barrier agents to reduce adhesion formation and bladder drainage with indwelling catheter prior to surgery. At present not much evidence is there to suggest whether the type of uterine incision, uterus exteriorization or foregoing bladder flap creation can prevent bladder injury. ${ }^{4}$ More research is required in this aspect.

A thorough clinical examination and appropriate diagnostic aids help identify this iatrogenic complication. Pelvic ultrasonography, sonohysterosalpingography, colour Doppler, retrograde cystourethrography and IV pyelography are important diagnostic modalities that help diagnose this condition. Treatment of vesico-uterine fistula is most often surgical with a transabdominal approach being the method of choice if it is a large fistula, connects high enough on the posterior wall of the urinary bladder or involves the ureters. Omental flap interposition assists in its successful repair..$^{5}$ Post-repair, bladder integrity needs to be tested with $200 \mathrm{ml}$ of saline coloured with methylene blue or indigo-carmine. Postoperatively the urinary catheter should be left in place for upto 3 weeks. The follow-up of patients with adequately repaired vesico-uterine fistulas following caesarean sections is of vital importance during subsequent pregnancies. ${ }^{6}$ 


\section{CONCLUSION}

VUF following caesarean section is an iatrogenic complication. It can present in early postpartum period with acute abdomen or late as Youssef's syndrome. Early repair postoperatively can give good results. Meticulous practice of obstetric and surgical principles, intraoperative diagnosis and adequate surgical repair can prevent this severe morbid condition.

\section{ACKNOWLEDGMENTS}

Authors acknowledge the help and support extended by the Department of Urology, Mahatma Gandhi Medical College and Research Institute, Pondicherry (India) in the operative management of the presented case.

Funding: No funding sources

Conflict of interest: None declared

Ethical approval: Not required

\section{REFERENCES}

1. Abu J, Wong MYC, Foo KT, Yu SL. A case Report on Vesico-uterine fistula, a very rare complication of lower caesarean section. Singapore Med J. 2000;41:554-6.

2. Iloabachie GC, Njoku O. Vesico-uterine fistula. Br J Urol. 1985;57:438-9.

3. Varawalla NY, Krishna UR. Conservative management of traumatic vesico-cervical fistula: a case report. J Postgrad Med. 1987;33:102-4.

4. Tarney CM. Bladder injury during caesarean delivery. Curr Womens Health Rev. 2013;9:70-6.

5. Shinde G, Rathod K, Dedhia M, Shyamkul A, Shrikhande A, Kotabagi F. Youssef's Syndrome. Bombay Hospital J. 2011;53:681-3.

6. Issa MM, Schmid HP, Stamey TA. Youssef's Syndrome: preservation of uterine function with subsequent successful pregnancy following surgical repair. Urol Int. 1994;52:220-2.

Cite this article as: Pallavee $\mathrm{P}$, Behera J, Samal R. A case of post-caesarean vesico-uterine fistula: a rare entity becoming common. Int J Reprod Contracept Obstet Gynecol 2017;6:5145-7. 